\title{
Postural habits and weight of backpacks of Portuguese adolescents: Are they associated with scoliosis and low back pain?
}

\author{
Beatriz Minghelli $^{\mathrm{a}, \mathrm{b}, *}$, Raul Oliveira ${ }^{\mathrm{c}}$ and Carla Nunes ${ }^{\mathrm{b}}$ \\ ${ }^{a}$ School of Health Jean Piaget-Algarve, Piaget Institute, Silves, Portugal \\ ${ }^{\mathrm{b}}$ National School of Public Health, NOVA University of Lisbon, Lisbon, Portugal \\ ${ }^{c}$ Faculty of Human Kinetics, Technical University of Lisbon, Lisbon, Portugal
}

Received 28 October 2014

Accepted 13 October 2015

\begin{abstract}
.
BACKGROUND: The adoption of incorrect postures or carrying overweight backpacks may contribute to the development of musculoskeletal disorders in school children.

OBJECTIVE: This study evaluated the weight of backpacks and the postural habits adopted in schools by Portuguese adolescents, and their association with scoliosis and low back pain (LBP).

METHOD: The sample comprised 966 Portuguese students, aged between 10 and 16 years. The instruments included a questionnaire to characterize the presence of LBP and the postural habits adopted by students, the weighing of backpacks and a scoliometer to evaluate scoliosis.

RESULTS: No association was observed between assuming incorrect postures and carrying overweight backpacks, in students with scoliosis. Students who adopted incorrect sitting postures had 1.77 times the risk (95\% CI: $1.32-2.36 ; p<0.001)$ of developing LBP; those positioned incorrectly whilst watching TV and playing games had 1.44 times the risk (95\% CI: $1.08-1.90 ; p=0.012$ ) of developing LBP; and those standing incorrectly had 2.39 the risk (95\% CI: $1.52-3.78 ; p<0.001)$ of developing LBP.
\end{abstract}

CONCLUSIONS: The results revealed that students who sat with the spine positioned wrongly, as well as those who were standing incorrectly, were more likely to present with LBP.

Keywords: Back disorders, behavioral risk factors, epidemiology, teenagers

\section{Introduction}

In children and adolescents, the environment particularly in schools may contribute to the development of musculoskeletal disorders. At this time, the bone structure is developing $[1,2]$ and disorders

*Address for correspondence: B. Minghelli, Instituto Piaget, Escola Superior de Saúde Jean Piaget, Algarve, Enxerim 8300025, Silves, Portugal. Tel.: +351 282440 170; E-mail: beatriz. minghelli@silves.ipiaget.pt. can cause orthopaedic and rheumatologic diseases [3]. The cause of musculoskeletal disorders in adolescents is multifactorial, involving for example participation in sports or exercise, long periods of inactivity, poor posture while sitting, and wearing backpacks that are overweight $[4,5]$.

In most schools, the design of the furniture does not take into account the anthropometric dimensions of users in different age groups. This situation leads to students adopting incorrect postures in classrooms, especially during reading and writing tasks upon 
which they spend most of their time [6]. Adopting an inappropriate sitting posture for long periods may lead to greater fatigue in the muscles, and may cause increased pressure on the intervertebral discs and ligaments [7].

Wearing backpacks that are too heavy is another factor that can contribute to the development or aggravation of musculoskeletal disorders [5, 8-14]. The weight of the backpack appears to be strongly associated with the occurrence of musculoskeletal disorders, especially in the shoulders, neck and back [5]. The wrong positioning of backpacks can lead to postural changes; for example, carrying them on one side may cause a lateral inclination of the spine and a depression on the side of the shoulder $[12,15]$, causing increased pressure on the lateral region of the intervertebral disc on the load side and leading to a rotation of the vertebral body associated with a spine inclination [7]. Negrini and Negrini [16] analyzed the weight and form of backpack transport in 43 adolescents $(12.5 \pm 0.5$ years $)$ in different conditions, and verified that the asymmetrical carriage of the backpack caused a posteriorisation and elevation of the shoulder on the side of the load with a lateral inclination of the trunk. When transport was symmetrical with a heavy backpack, an anterior flexion of the trunk was observed, associated with a lateral inclination.

The mechanical properties of the spine, improper spine alignment, asymmetrical distribution of loads (either by forces or displacements) and how the spine is supported may lead to aggravation of scoliosis. Thus, biomechanical and environmental factors can affect spine alignment and are often involved in the pathogenesis of idiopathic scoliosis [17].

Not only scoliosis, but also nonspecific low back pain (LBP) in students is a subjects of growing importance in the literature. The attention of the scientific community has recently been drawn to the problem of the use of backpacks that exceed the legal weight limits for adult workers; these backpacks may be related, although not directly, to LBP [19-21]. There is still controversy whether an excessively heavy backpack by itself can lead to LBP; postural variations also have been considered as possible risk factors for the development of back pain in children and adolescents [16].

This study aimed to determine the weight of backpacks and to assess the postural habits adopted at school and at home in adolescents in southern Portugal, and to explore possible associations of these factors with pre-existing scoliosis and LBP.

\section{Methods}

This epidemiological, cross-sectional study was approved by the Ethics Committee of the Regional Health Administration of the Algarve, the Regional Directorate of Education of the Algarve, the Directorate General for Innovation and Curriculum Development, the Ministry of Education and Science and the Schools heads that participated in the project. After informing the students' parents and guardians about the objectives and method of the study, we asked for their consent for their children to participate, ensuring that the principles and fundamental entitlements applicable to humans by ethics codes were taken into consideration. Written informed consent was obtained from all students' parents or guardians.

\subsection{Population and sample}

The population involved students enrolled in public schools $(26,217$ students between the fifth and ninth grades) [22] from all counties of the Algarve region in southern Portugal, of both sexes, aged between 10 and 16 years. The calculation of the sample size was based on the estimated annual prevalence of LBP for the age group analyzed (40\% reported in national and international studies, with an error of $3 \%$ ) [23-25], which led to the value of 986 individuals [26]. We opted for the use of the prevalence of LBP instead of scoliosis, since the prevalence of scoliosis is much lower than that of LBP.

Considering the issues of non-response and logistics and to facilitate the division of students by schools, it was proposed that a sample size of approximately 1,000 students (2nd and 3rd cycles) of the Algarve region would be appropriate.

Three inclusion criteria were defined: 1) presence at school on the data collection days: 2) consent provided by parent or guardian and 3) willingness to participate. No exclusion criterion was defined. A stratified random sample was used, based on counties, and assuming geographical heterogeneity. Schools were selected randomly if there was more than one school in the county. Classes were then randomly selected from each of the included schools until the desired number of students per school was obtained. The size of samples by counties was proportional to the number of students enrolled in the public schools in each county. There were three classes of counties: Small $(<1,000$ students), medium $(1,001-2,000$ students) and large ( $>2,000$ students). Different sizes 
of sample were required for each (40, 70 and 100 students, respectively).

\subsection{Instruments and procedures}

\subsubsection{Scoliometer}

For the identification of scoliosis we used the scoliometer produced by Pedihealth in Oy, Finland. Several studies have found a good inter- and intrarater reliability of the scoliometer, with a sensitivity of $90.6 \%$ and a specificity of $79.8 \%$ [27-29]. Students were asked to flex their trunk whilst looking down and keeping their feet at a distance of $15 \mathrm{~cm}$ with their arms relaxed; the instrument then was positioned perpendicular to the analysed vertebrae [27]. The scoliometer was positioned to measure the angle of trunk rotation at the mid-thoracic region (vertebrae $\mathrm{T} 4$ to $\mathrm{T} 8$ ); the thoracolumbar region (T12 to L1); and the lumbar region (L2 to L5). The criteria for choosing these sites were advocated by Grivas et al. [30].

The presence of a hump corresponding to the projection of the ribs or lumbar muscles mass due to the rotation of the vertebral body was determined by lateral curvature of the spine. In each of the three regions described above, trunk asymmetry on the right side was indicated by a greater hump on the right, defined as right asymmetry, and a hump on the left side was defined as left asymmetry [1, 31].

Regarding severity, individuals recording a value between $0^{\circ}$ and $4^{\circ}$ were classified as having an angle of trunk rotation (ATR) within normal limits [30]. An ATR between $5^{\circ}$ and $6^{\circ}$ was termed trunk rotation with intermediate asymmetry (corresponding to at least $10^{\circ}$ of lateral inclination, as measured by the Cobb method), and an ATR equal to or greater than $7^{\circ}$ indicated the presence of scoliosis of severe trunk asymmetry (corresponding to $30^{\circ}$ by the Cobb method) $[32,33]$.

Current recommendations suggest that we should intervene only in the presence of values near $30^{\circ}$ as measured by the Cobb method. Based on this, it is expected to detect $95 \%$ of all cases eligible for treatment, imposing an acceptable low rate of false-negative [34-38]. The value of $5^{\circ}$, using the scoliometer has been shown to have a sensitivity of $100 \%$ and $47 \%$ specificity for scoliosis detection, while the value of $7^{\circ}$ increases the specificity to $86 \%$ but decreases the sensitivity to $83 \%[38,39]$. With a value of $7^{\circ}$, Adobor et al. [39] reported 69\% sensitivity and $99 \%$ specificity in detecting adolescent idiopathic scoliosis in the study population.

\subsubsection{Low Back Pain and Postural Habits Questionnaire}

A Low Back Pain and Postural Habits Questionnaire was developed for this study, aiming to describe the presence of LBP and the postural habits adopted by the students at home and at school. The first part of the questionnaire, developed and validated by Oliveira et al. [40], contained items about the sociodemographic characteristics of the population, the presence of LBP in the last year and how much time was spent per week on activities such as watching television and playing video games/computer. The presence of LBP was characterized by the presence of symptoms in the lumbar region that included pain, muscle tension or stiffness [41].

The second part of the questionnaire was adapted from the Assessment of Postural Habit Questionnaire of Rebolho [42] and included questions about the postural habits adopted at school and at home and the mode of transportation of the school backpack, with the use of images aiming to reduce information error bias in completing the questionnaire.

Students were asked to describe their own postures when sitting and standing, picking an object off the floor and watching television and/or playing games. If a student habitually assumed more than one of the postures illustrated in the questionnaire, they were asked to indicate the stance that he/she adopted with greater frequency. The questionnaire was filled in by the respondents, but researchers were always present to clarify any questions related to its completion.

We conducted a pretest of the questionnaire in a sample of 47 students of the Secondary School Poeta Al Berto in Sines, Alentejo, Portugal, of both sexes, with $32(68.1 \%)$ girls, aged between 13 and 20 years (16.2 \pm 1.6 years). This pilot test allowed us to understand the degree of difficulty the students experienced in answering the questions, as well as the time they spent to complete it.

\subsubsection{Weighing of backpack}

For the school backpack weight measurement, we used a SECA 780 digital scale with $150 \mathrm{~kg}$ of capacity and precise to within $100 \mathrm{~g}$. We chose to perform only one weight measurement for each backpack for logistical reasons, and also because the students could have manipulated the weights if they had been told the purpose of weighing their backpacks. A backpack was classified as having excessive weight if it was more than $10 \%$ of the owner's body weight [18, 43-45], which was measured by the same scale. During their weight measurement, students were asked to stand 
erect, without shoes, wearing their normal clothes but excluding coats, and with their arms extended along the trunk [46].

\subsection{Data analysis}

The statistical analysis was performed with the Statistical Package for Social Sciences (SPSS) version 19.0. After a statistics descriptive approach, various associations between postural habits and the weight of the backpack with scoliosis and LBP were assessed using inferential statistics, specifically by the chisquare test for independence. Some numbers were small and, in order to satisfy the requirements of the chi-square test, the variables of postural habits were divided into two groups: Correct and incorrect posture.

Based on the definition of two different phases of the growth period, two groups of students were considered in the analyses: Age group 1 - students aged between 10 and 12 years; age group 2 - students between 13 and 16 years. It was assumed that individuals from age group 1 were not yet in the period of pronounced growth, particularly the boys; between 13 and 16 years the adolescents were in the period of accelerated pubertal growth [47].

The influence of the variables of postural habits and backpack weight upon the presence of LBP was assessed using binary logistic regressions. Models were evaluated using Omnibus, Hosmer-Lemeshow and Nagelkerke statistics. Odds ratios (OR), crude and adjusted (method: Enter), final model (method: Forward) and respective confidence intervals (CI) were presented. Statistical significance was set at 0.05 .

\section{Results}

The sample comprised 966 students (20 students did not respond) aged between 10 and 16 years (12.24 \pm 1.53 years); 437 (45.2\%) were male and 529 (54.8\%) female. The students were divided into two age groups; $574(59.4 \%)$ were between 10 and 12 years and $392(40.6 \%)$ between 13 and 16 years. Two hundred and four $(21.1 \%)$ students belonged to the 5th grade; $236(24.4 \%)$ to the 6th grade; 271 (28.1\%) to the 7 th grade; $143(14.8 \%)$ to the 8 th grade; and 112 $(11.6 \%)$ to the 9 th grade. Table 1 shows the sample distribution by municipality of the Algarve region.

An intermediate trunk rotation (values of $5^{\circ}$ and $6^{\circ}$ in the scoliometer) was observed in $106(11 \%)$
Table 1

Sample distribution by municipalities of the Algarve region

\begin{tabular}{lc}
\hline $\begin{array}{l}\text { Municipalities of the } \\
\text { Algarve region }\end{array}$ & $\begin{array}{c}\text { Absolute frequency } \\
\text { (relative frequency) }\end{array}$ \\
\hline Albufeira & $128(13.3 \%)$ \\
Faro & $108(11.2 \%)$ \\
Portimão & $102(10.6 \%)$ \\
Loulé & $94(9.7 \%)$ \\
Silves & $88(9.1 \%)$ \\
Vila Real de Santo António & $77(8 \%)$ \\
Lagoa & $67(6.9 \%)$ \\
Olhão & $66(6.8 \%)$ \\
Lagos & $64(6.6 \%)$ \\
Castro Marim & $43(4.5 \%)$ \\
Aljezur & $37(3.8 \%)$ \\
Alcoutim & $35(3.6 \%)$ \\
São Brás do Alportel & $31(3.2 \%)$ \\
Vila do Bispo & $26(2.7 \%)$ \\
\hline
\end{tabular}

students and severe trunk rotation (values of ATR equal to or greater than $7^{\circ}$ ) was observed in 41 (4.2\%), most being seen in girls (Table 2). For the analysis of scoliosis curvature, we combined the data related to the moderate and severe asymmetric curvature variables in order to assess their relationship with associated risk factors. For the associations between LBP and other variables, we considered only LBP reported to have occurred in the last year. Table 3 shows the descriptive statistics of associations between LBP and scoliosis with the variables used in this study.

The weight of the backpacks ranged from $0.8 \mathrm{~kg}$ to $11.1 \mathrm{~kg}(4.37 \pm 1.51 \mathrm{~kg})$. Considering the subgroup of students who carried overweight backpacks, the average backpack weight was $5.52 \pm 1.21 \mathrm{~kg}$, with a maximum of $11.1 \mathrm{~kg}$. Three hundred and fourteen $(32.5 \%)$ students were carrying backpacks with weights over $10 \%$ to $15 \%$ of their body weight, and $83(8.6 \%)$ with weights above $15 \%$ to $27.4 \%$ of their body weight. Considering only the students with overweight backpacks, the maximum percentage of body weight was $27.4 \%(13.47 \pm 3.21 \%)$. Of the $397(100 \%)$ students carrying an overweight backpack, $130(32.7 \%)$ belonged to the 5th grade (Table 4).

Table 5 shows the relationship between the presence of LBP and gender, age group and postural habits obtained from the application of logistic regression models. In the adjusted model, the values obtained in the Omnibus, Hosmer-Lemeshow and Nagelkerke statistics were respectively: $p<0.001, p=0.944$ and $\mathrm{R}^{2}=0.112$, being considered mathematical models valid for conducting the analysis. The cutoff value was 0.4 . The specificity of the model was $45.7 \%$ and 
Table 2

Association between the presence of trunk rotation with gender and age group

\begin{tabular}{llccc}
\hline Variables (n, \%) & & $\begin{array}{c}\text { Normal limits } \\
\left(\mathrm{ATR}<5^{\circ}\right) \\
(819,84.8 \%)\end{array}$ & $\begin{array}{c}\text { Intermediate trunk } \\
\text { rotation }\left(\mathrm{ATR}=5^{\circ}, 6^{\circ}\right) \\
(106,11 \%)\end{array}$ & $\begin{array}{c}\text { Severe trunk rotation } \\
\left(\mathrm{ATR} \geq 7^{\circ}\right) \\
(41,4.2 \%)\end{array}$ \\
\hline \multirow{2}{*}{ Gender } & Male $(437,45.2 \%)$ & $383(87.6 \%)$ & $37(8.5 \%)$ & $17(3.9 \%)$ \\
\multirow{4}{*}{ Age group } & Female $(529,54.8 \%)$ & $436(82.4 \%)$ & $69(13 \%)$ & $24(4.5 \%)$ \\
& $10-12$ years $(574,59.4 \%)$ & $491(85.5 \%)$ & $63(11 \%)$ & $20(3.5 \%)$ \\
& $13-16$ years $(392,40.6 \%)$ & $328(83.7 \%)$ & $43(11 \%)$ & $21(5.4 \%)$ \\
\hline
\end{tabular}

the sensitivity was $76.5 \%$. The overall corrected percentage was $60.2 \%$. The area under the ROC curve was $0.687(0.654-0.721)$.

In the adjusted model, it was found that students who sit with their spine positioned incorrectly have 1.77 times the risk (95\% CI: $1.32-2.36 ; p<0.001$ ) of developing symptoms of LBP; students who are positioned incorrectly when watching TV and playing video games have 1.44 times the risk $(95 \% \mathrm{CI}$ : $1.08-1.90 ; p=0.012)$; and those who stand incorrectly have a probability of 2.39 (95\% CI: $1.52-3.78$; $p<0.001$ ) of developing LBP.

\section{Discussion}

The present study revealed that most of the students assessed frequently adopted incorrect postures at school and at home, especially when sitting. Regarding the hours spent on sedentary activities, most students said they watched television and played video games for up to 10 hours per week. These results differ from data obtained from the Health Behaviour of School-Aged Children (HBSC) survey [48], that evaluated 6,903 students of 6th, 8th and 10th school grades, reporting that most $(61.3 \%)$ watched television between one half hour to three hours per day; $10.3 \%$ watched less than 10 hours per week. Regarding video games, $68.7 \%$ played at least one hour per week, $26 \%$ between one and six hours per week and $5.4 \%$ for a period not less than seven hours per week. Most students (58.4\%) carried their backpacks with both straps on each shoulder. The same carriage was observed by Lopes [49], who evaluated 288 students of 5th and 6th school grade (mean age: $10.9 \pm 1.08$ years) from two schools in the Porto area and found that this type of transportation was performed by $53 \%$ of students; $8 \%$ carried backpacks with a strap on one shoulder; and $4 \%$ used backpacks with wheels. Skaggs et al. [44] evaluated 1,540 adolescents aged 11 to 14 years and found $81 \%$ preferred to carry their backpacks by using two straps, and $14 \%$ by one strap. Pascoe et al. [12] found that the form of transport most used by students $(73.1 \%)$ was with a strap supported on one shoulder.

The present study found that a high percentage of students $(41.1 \%)$ carried an excessively heavy backpack (greater than $10 \%$ of their body weight); the average weight of all of the backpacks was $4.37 \pm 1.51 \mathrm{~kg}$ with a maximum of 11.1 kilograms. These values are similar to those reported by Skaggs et al. [44] in which the average backpack weight was $4.0 \pm 1.7 \mathrm{~kg}$ with a maximum of 11.4 kilograms. Lopes [49] recorded an average weight of $6.44 \pm 2.37 \mathrm{~kg}$ with a maximum of $6.68 \mathrm{~kg}$; however, the latter study only evaluated students in the 5th and 6th school grades, whereas the present study also included students from the 7th to 9th grade.

The average backpack weight evaluated by Pascoe et al. [12] was $7.7 \mathrm{~kg}$; by Sheir-Ness et al. [50], $8.3 \mathrm{~kg}$; and by Negrini et al. [20], $8.75 \mathrm{~kg}$, all higher than those found in this study. Negrini et al. [20] found that $90.1 \%$ of the total weight of the backpack consisted of equipment necessary for school work; the present study did not investigate the purpose of the backpack contents.

Lopes [49] reported that $48 \%$ of students carried backpacks with weights up to $15 \%$ of their body weight; $50 \%$ of these were between $15 \%$ to $30 \%$. Sheir-Ness et al. [50] reported that most students $(79.6 \%)$ carried their backpacks with a weight exceeding $10 \%$ of their body weight; $47 \%$ carried more than $15 \%$ of their body weight; and $18.9 \%$ more than $20 \%$ of their body weight. The data of the present study found that, in the subgroup of students carrying excess weight, $32.5 \%$ carried a backpack weighing $10 \%$ to $15 \%$ of their body weight; and $8.6 \%$ between $15 \%$ and $27 \%$ of their body weight.

The results obtained in this study revealed that students of the 5th school grade accounted for the majority of students carrying school backpacks with weights above $10 \%$ of their body weight; and the 9th grade students tended to carry less proportional weight in their backpacks. Generally, students 
Table 3

Associations between the presence of LBP and scoliosis with the variables of this study

\begin{tabular}{|c|c|c|c|c|c|c|c|c|}
\hline \multirow[t]{2}{*}{ Variables n $(\%)$} & & \multirow[t]{2}{*}{ Grouped variables } & \multicolumn{2}{|c|}{ Low back pain } & \multirow[t]{2}{*}{$p$-value } & \multicolumn{2}{|c|}{ Scoliosis } & \multirow[t]{2}{*}{$p$-value } \\
\hline & & & $\begin{array}{c}\text { Absence } \\
(510,52.8 \%)\end{array}$ & $\begin{array}{c}\text { Presence } \\
(456,47.2 \%)\end{array}$ & & $\begin{array}{c}\text { Absence } \\
(819,84.8 \%)\end{array}$ & $\begin{array}{c}\text { Presence } \\
147(15.2 \%)\end{array}$ & \\
\hline \multirow[t]{4}{*}{ Sitting posture - spine position } & $\begin{array}{l}\text { Sitting with the spine in extension and pushed } \\
\text { back against the chair }(419,43.4 \%)\end{array}$ & Correct $(419,43.4 \%)$ & $274(65.4 \%)$ & $145(34.6 \%)$ & \multirow[t]{4}{*}{$<0.001$} & $364(86.9 \%)$ & $55(13.1 \%)$ & \multirow[t]{4}{*}{0.11} \\
\hline & $\begin{array}{l}\text { Sitting with bent spine and leaning against the } \\
\text { chair }(325,33.6 \%)\end{array}$ & Incorrect $(547,56.6 \%)$ & $236(43.1 \%)$ & $311(56.9 \%)$ & & $455(83.2 \%)$ & $92(16.8 \%)$ & \\
\hline & $\begin{array}{l}\text { Sitting with the spine in extension and away } \\
\text { from the chair }(146,15.1 \%)\end{array}$ & & & & & & & \\
\hline & $\begin{array}{l}\text { Sitting with bent spine and away from the chair } \\
(76,7.9 \%)\end{array}$ & & & & & & & \\
\hline \multirow[t]{2}{*}{ Sitting posture - gluteal region } & Leaning against the chair $(637,65.9 \%)$ & Correct $(637,65.9 \%)$ & $371(58.2 \%)$ & $266(41.8 \%)$ & \multirow[t]{2}{*}{$<0.001$} & $538(84.5 \%)$ & $99(15.5 \%)$ & \multirow[t]{2}{*}{0.77} \\
\hline & Away from the chair $(329,34.1 \%)$ & Incorrect $(329,34.1 \%)$ & $139(42.2 \%)$ & $190(57.8 \%)$ & & $281(85.4 \%)$ & $48(14.6 \%)$ & \\
\hline \multirow[t]{4}{*}{ Sitting posture - feet } & Flat on the floor $(587,60.8 \%)$ & Correct $(587,60.8 \%)$ & $331(56.4 \%)$ & $256(43.6 \%)$ & \multirow[t]{4}{*}{0.006} & $493(84 \%)$ & $94(16 \%)$ & \multirow[t]{4}{*}{0.41} \\
\hline & $\begin{array}{l}\text { Reach the floor, but only with the fingertips } \\
(217,22.5 \%)\end{array}$ & Incorrect $(379,39.2 \%)$ & $179(47.2 \%)$ & $200(52.8 \%)$ & & $326(86 \%)$ & $53(14 \%)$ & \\
\hline & $\begin{array}{l}\text { Reach the floor, but it had to be positioned at } \\
\text { the end of the chair seat }(126,13 \%)\end{array}$ & & & & & & & \\
\hline & Hung $(36,3.7 \%)$ & & & & & & & \\
\hline \multirow[t]{3}{*}{ Standing posture } & $\begin{array}{l}\text { With the spine in extension, maintaining the } \\
\text { physiological curvature }(853,88.3 \%)\end{array}$ & Correct $(853,88.3 \%)$ & $479(56.2 \%)$ & $374(43.8 \%)$ & \multirow[t]{3}{*}{$<0.001$} & $729(85.5 \%)$ & $124(14.5 \%)$ & \multirow[t]{3}{*}{0.12} \\
\hline & $\begin{array}{l}\text { With the bent spine in the dorsal region, } \\
\text { increasing thoracic kyphosis }(94,9.7 \%)\end{array}$ & Incorrect $(113,11.7 \%)$ & $31(27.4 \%)$ & $82(72.6 \%)$ & & $90(79.6 \%)$ & $23(20.4 \%)$ & \\
\hline & $\begin{array}{l}\text { With the lumbar spine in hyperextension, } \\
\text { increasing lordotic curvature }(19.2 \%)\end{array}$ & & & & & & & \\
\hline \multirow[t]{2}{*}{ Pick up an object from the floor } & $\begin{array}{l}\text { With knee flexion, keeping the spine in } \\
\text { extension }(463,47.9 \%)\end{array}$ & Correct $(463,47.9 \%)$ & $270(58.3 \%)$ & $193(41.7 \%)$ & \multirow[t]{2}{*}{0.001} & $388(83.8 \%)$ & $75(16.2 \%)$ & \multirow[t]{2}{*}{0.42} \\
\hline & $\begin{array}{l}\text { With flexion of spine, keeping the knees } \\
\text { extended }(503,52.1 \%)\end{array}$ & Incorrect $(503,52.1 \%)$ & $240(47.7 \%)$ & $263(52.3 \%)$ & & $431(85.7 \%)$ & $72(14.3 \%)$ & \\
\hline \multirow[t]{4}{*}{$\begin{array}{l}\text { Posture for watching TV and/or } \\
\text { playing games }\end{array}$} & $\begin{array}{l}\text { Sitting with the spine in extension } \\
\text { (maintaining the physiological curvatures) } \\
\text { and leaning against the chair with feet on the } \\
\text { ground }(439,45.4 \%)\end{array}$ & Correct $(439,45.4 \%)$ & $273(62.2 \%)$ & $166(37.8 \%)$ & \multirow[t]{4}{*}{$<0.001$} & $376(85.6 \%)$ & $63(14.4 \%)$ & \multirow[t]{4}{*}{0.53} \\
\hline & In lateral decubitus $(304,31.5 \%)$ & Incorrect $(527,54.6 \%)$ & $237(45 \%)$ & $290(55 \%)$ & & $443(84.1 \%)$ & $84(15.9 \%)$ & \\
\hline & $\begin{array}{l}\text { In supine with the cervical spine in flexion } \\
(131,13.6 \%)\end{array}$ & & & & & & & \\
\hline & $\begin{array}{l}\text { Sitting without support to spine and in posture } \\
\text { of flexion }(92,9.5 \%)\end{array}$ & & & & & & & \\
\hline \multirow[t]{3}{*}{ Time watching TV (per week) } & Up to 5 hours $(446,46.2 \%)$ & Until 10 hours per week $(749,77.5 \%)$ & $399(53.3 \%)$ & $350(46.7 \%)$ & \multirow[t]{3}{*}{0.59} & $636(84.9 \%)$ & $113(15.1 \%)$ & \multirow[t]{3}{*}{0.83} \\
\hline & Between 6 and 10 hours $(303,31.4 \%)$ & & & & & & & \\
\hline & $\begin{array}{l}\text { Between } 11 \text { and } 15 \text { hours }(127,13.1 \%) \\
\text { More than } 15 \text { hours }(90,9.3 \%)\end{array}$ & Above 10 hours per week $(217,22.5 \%)$ & $111(51.2 \%)$ & $106(48.8 \%)$ & & $183(84.3 \%)$ & $34(15.7 \%)$ & \\
\hline
\end{tabular}


Time playing games/computer (per week)

Up to 5 hours $(649,67.2 \%)$

Between 6 and 10 hours $(184,19 \%)$

Between 11 and 15 hours $(73,7.6 \%)$

More than 15 hours $(60,6.2 \%)$

With both handles of the backpack on each

shoulder $(564,58.4 \%)$

With one of the handles on a shoulder (158, $16.4 \%)$

With the two handles on the same shoulder

$$
(84,8.7 \%)
$$

With cross handle on the trunk $(64,6.6 \%)$

By hand $(9,0.9 \%)$

In the anterior region of the trunk with both

handles on each shoulder $(2,0.2 \%)$

Backpack with wheels (trolley) $(4,0.4 \%)$

Adequate $(569,58.9 \%)$

Excess of weight $(397,41.1 \%)$

Male $(437,45.2 \%)$

Female $(529,54.8 \%)$

$10-12$ years $(574,59.4 \%)$

$13-16$ years $(392,40.6 \%)$

Gender

Age group
Until 10 hours per week $(833,86.2 \%)$

$437(52.5 \%)$

$396(47.5 \%)$

0.64

$707(84.9 \%) \quad 126(15.1 \%)$

0.84

Above 10 hours per week $(133,13.8 \%)$

$73(54.9 \%)$

$60(45.1 \%)$

$112(84.2 \%)$

$21(15.8 \%)$

$333(59 \%)$

$231(41 \%)$

$177(44 \%)$

$225(56 \%)$

$<0.001$

$478(84.8 \%)$

$86(15.2 \%)$

$341(84.8 \%)$

$61(15.2 \%$

\begin{tabular}{llllll}
$292(51.3 \%)$ & $277(48.7 \%)$ & 0.29 & $487(85.6 \%)$ & $82(14.4 \%)$ & 0.41 \\
$218(54.9 \%)$ & $179(45.1 \%)$ & & $332(83.6 \%)$ & $65(16.4 \%)$ & \\
$273(62.5 \%)$ & $164(37.5 \%)$ & $<0.001$ & $383(87.6 \%)$ & $54(12.4 \%)$ & 0.02 \\
$237(44.8 \%)$ & $292(55.2 \%)$ & & $436(82.4 \%)$ & $93(17.6 \%)$ & \\
$328(57.1 \%)$ & $246(42.9 \%)$ & 0.001 & $491(85.5 \%)$ & $83(14.5 \%)$ & 0.43 \\
$182(46.4 \%)$ & $210(53.6 \%)$ & & $328(83.7 \%)$ & $64(16.3 \%)$ & \\
\hline
\end{tabular}


Table 4

Distribution of weight backpack school classification by school grade

\begin{tabular}{|c|c|c|c|c|c|c|}
\hline \multirow[t]{2}{*}{ Weight of backpack } & \multicolumn{5}{|c|}{ School year } & \multirow[t]{2}{*}{ Total } \\
\hline & $5^{\circ}$ & $6^{\circ}$ & $7^{\circ}$ & $8^{\circ}$ & $9^{\circ}$ & \\
\hline Adequate (up to $10 \%$ of body weight) & $74(13 \%)$ & $139(24,4 \%)$ & $153(26,9 \%)$ & $108(19 \%)$ & $95(16,7 \%)$ & $569(100 \%)$ \\
\hline Excess of weight & $130(32,7 \%)$ & $97(24,4 \%)$ & $118(29,7 \%)$ & $35(8,8 \%)$ & $17(4,3 \%)$ & $397(100 \%)$ \\
\hline
\end{tabular}

Table 5

Relationship between the event the presence of LBP and postural habits

\begin{tabular}{|c|c|c|c|}
\hline Variables & $\begin{array}{l}\text { Odds Ratio }_{\text {crude }} \\
\text { (CI 95\%); }\end{array}$ & $\begin{array}{l}\text { Odds Ratio }_{\text {adjusted }}{ }^{* *} \\
\text { (CI 95\%); }\end{array}$ & $\begin{array}{l}\text { Final Model } \\
\text { (CI 95\%); p }\end{array}$ \\
\hline Gender & $2.05(1.58-2.65) ; p<0.001$ & & ---------- \\
\hline Age group & $1.54(1.19-1.99) ; p=0.001$ & & \\
\hline Sitting posture - spine position (correct posture*) & $2.49(1.91-3.24)$ & 2.28 (1.76-2.99); & $1.77(1.32-2.36)$ \\
\hline Incorrect posture & $p<0.001$ & $p<0.001$ & $p<0.001$ \\
\hline Sitting posture - gluteal region (correct posture*) & 1.91 (1.46-2.49); & 1.87 (1.42-2.47); & $1.39(1.04-1.87)$; \\
\hline Incorrect posture & $p<0.001$ & $p<0.001$ & $p=0.029$ \\
\hline Sitting posture - feet position (correct posture*) & 1.45 (1.12-1.87); & 1.43 (1.09-1.86); & \\
\hline Incorrect posture & $p=0.005$ & $p=0.009$ & \\
\hline Standing posture (correct posture*) & $3.39(2.19-5.23)$ & $3.19(2.04-4.97)$ & $2.39(1.52-3.78)$; \\
\hline Incorrect posture & $p<0.001$ & $p<0.001$ & $p<0.001$ \\
\hline Pick up an object from the floor (correct posture*) & 1.53 (1.19-1.98); & 1.43 (1.10-1.86); & \\
\hline Incorrect posture & $p=0.001$ & $p=0.007$ & \\
\hline Posture for watching TV and/or playing games (correct posture*) & $2.01(1.55-2.61)$ & $1.88(1.44-2.45)$ & $1.44(1.08-1.90)$; \\
\hline Incorrect posture & $p<0.001$ & $p<0.001$ & $p=0.012$ \\
\hline Time watching TV (per week) (up to 5 hours per week*) & 1.09 (0.81-1.47); & $1.13(0.83-1.54)$ & \\
\hline Between 6 and 10 hours per week & $p=0.582$ & $p=0.433$ & \\
\hline Time playing games/computer (per week) (Up to 5 hours per week*) & $0.91(0.63-1.31)$ & $1.00(0.68-1.47)$ & \\
\hline Between 6 and 10 hours per week & $p=0.603$ & $p=0.996$ & \\
\hline Mode of transportation of backpacks (correct posture*) & 1.83 (1.42-2.37); & 1.54 (1.18-2.02); & \\
\hline Incorrect posture & $p<0.001$ & $p=0.002$ & \\
\hline Weight of backpacks (correct posture*) & $0.87(0.67-1.12)$ & $0.97(0.74-1.27)$ & \\
\hline Incorrect posture & $p=0.271$ & $p=0.822$ & \\
\hline
\end{tabular}

belonging to more advanced school grades could be expected to carry more weight because of the greater number of subjects they studied, and their textbooks and notebooks of activities would also be larger and heavier. However, the opposite was observed in the present study. It should be pointed out that students of the 5th grade are less likely to be familiar with the needs of basic education and therefore might carry unnecessary material.

This research found no statistically significant association between scoliosis and incorrect postural habits and excessive weight of the backpack. A similar result was obtained by Grimmer et al. [51] who found no difference in postural response with a backpack weighing up to $10 \%$ of body weight compared to a lighter weight backpack, and could not support the rule of establishing a limit load of $10 \%$ of body weight.

The etiology of most scoliosis is unknown [52]; throughout the 18th and 19th centuries, it was believed that scoliosis was caused by bad posture.
Currently, the etiology of scoliosis is attributed to a wide variety of conditions ranging from poor posture to poor nutrition [53]. However, according to the Scoliosis Research Society [54] and the Spine Society of Australia [31], scoliosis does not result from carrying excessive or asymmetric loads, or by assuming wrong postures while sleeping and standing, or by spending many hours watching television. However, there is evidence of a possible contribution of environmental factors in the development of scoliosis or its association with asymmetries in the length of the skeleton $[55,56]$. Nevertheless, this study found that most students classified as having scoliosis sat with the spine positioned incorrectly, although this relationship was not statistically significant.

Low back pain had a higher annual prevalence compared to the presence of scoliosis, which is in agreement with other studies [25, 57-65]. Low back pain is now very common in adolescents in general, since they participate in a number of activities without having a good level of strength in the abdominal 
musculature and spine extensors, and exhibit limited flexibility of the hamstring muscles [54].

Lopes [49] reported that $83 \%$ of students associated shoulder, cervical and lumbar region pain with the use of a backpack; Negrini and Carabalona [19] observed that $46.1 \%$ of adolescents reported that their school backpack was the cause of their back pain. Data from the present study found no statistically significant relationship between the presence of LBP and excessive weight of the backpack. This observation could be explained by the care taken by a student with LBP to minimize the pain; in other words, the LBP could have arisen as a result of carrying too much weight and, once the LBP was present, the student could be careful not to carry excess weight so as not to aggravate the symptoms. For example, Skaggs et al. [44] found that $37 \%$ of adolescents reported back pain, $34 \%$ limited their activity due to pain and $82 \%$ believed their backpack could be causing the pain; however, in this latter study, it was found that the pain was associated with the use of an overweight backpack $(p=0.001)$. Sheir-Ness et al. [50] evaluated 1,122 students, aged between 12 and 18 years, and also found that excessive backpack weight was associated with back pain (Odds ratio: 1.98, $p<0.0001$ ).

The present study revealed that $49 \%$ of students with LBP carried their backpack incorrectly. This relationship was statistically consistent; these students were 1.83 times more likely than those carrying their backpacks correctly to exhibit LBP. These aspects should be considered in future longitudinal studies.

Korovessis et al. [66] verified that the asymmetrical transport of backpacks was associated with LBP; students carrying their backpack asymmetrically were five times more likely to develop LBP compared with students who carried symmetrically. Trevelyan and Legg [67] evaluated 245 students in New Zealand, aged 11 to 14 years, and found that asymmetric transport of the backpack showed a positive relationship with LBP. However, Skaggs et al. [44] found that the use of one or two straps for carrying the backpack had no significant association with back pain; other studies [62, 67-73] also found no association.

The effect of backpack weight on posture in children and adolescents should be carefully evaluated. Laws protect workers against carrying heavy loads, but there is no law that prohibits the transportation of excessive loads by children and adolescents in whom the consequences may include postural changes and pain. Furthermore, several studies have found that the presence of back pain in young people is related to back pain in adult life [74-76]. However, there is still much controversy regarding the possible consequences of using backpacks, and the most appropriate weight for each child [10].

It is assumed that muscle fatigue is a major contributor to the pain felt by students while using the backpacks, however, to date, there is no study that has used Electromyography (EMG) to assess muscle activity in children [77].

There was no association between carrying excess weight and musculoskeletal disorders in our sample. We suggest a longitudinal study should be carried out, with evaluation at different periods, to analyze the period of time that the student carries a backpack, the mode of transport with this backpack and the lifestyles of students, since these can be considered factors that could aggravate or predispose to LBP. Lower back pain has a multifactorial etiology and evolution, and the different factors that may contribute to the disorder should be assessed. If the results of such a longitudinal study showed a cause and effect situation regarding LBP and carrying an excessively heavy school backpack and/or inadequate postural habits, prevention strategies would be needed. These could include the adoption of guidelines concerning maximum load limits to be transported via school backpacks, adjusted for the body weight of each young person, with advice on the proper way to carry the backpack, and sport/physical activity that promotes healthy lifestyles.

This cross-sectional study has some limitations. For example, the weight of each backpack was only measured once and this measurement may not have been representative of the backpack's usual weight over the past year and even over the present year (the weight of backpacks can vary diary depending on the disciplines/homework/activities you have on each day). However, Lopes [49] found that the weight carried on each weekday did not change significantly. As previously mentioned, there is a possibility of the weight of the backpack being manipulated if the student had knowledge of when the evaluation days would take place.

Other factors that showed an association with a history of LBP in the previous year included the adoption of some incorrect postural habits, such as an incorrect sitting position in school, whilst watching TV and playing games, and standing. However we cannot exclude the possibility that a student with LBP may seek to adopt an incorrect posture whilst carrying the backpack to try to minimize the pain. The cross-sectional nature of this study does not allow 
the analysis of causality, only associations between variables.

Bockowski et al. [78] evaluated 36 patients hospitalized with LBP, aged 10 to 18 years, and found that incorrect posture, especially in the sitting position, was common in $13.9 \%$ of children. Murphy et al. [79] evaluated the sitting postures of 66 adolescents aged 11 to 14 years, these being recorded in classes using the method of Portable Ergonomic Observation and found significant associations between a flexed posture and LBP (flexed posture was considered as an angle greater than 20 degrees from the upright posture). Sjolie [80] reported that one of the situations in which students reported more pain was in the sitting posture in school, reported by $48 \%$ of students. Watson et al. [81] found that, in adolescents who had LBP, 94\% reported having difficulty in at least one of the nine activities included in the modified Hanover Low Back Pain Disability Questionnaire; the activities associated with the greatest difficulty were carrying school backpacks (65\%) and sitting at school (53\%). However, Widhe [82] found no association between LBP and postural habits.

The method of collecting data on postural habits through image analysis can lead to biased data, since the response may be influenced by perceptions of the ideal posture, which does not necessarily occur in daily life; that is, the questionnaire could lead to a correct answer but not corresponding to reality. Thus, we suggest further studies should include direct observations of postural habits adopted at home and school without prior student knowledge, since students could adopt correct postural behaviors on the days that would be evaluated.

Another limitation of this study included the crosssectional nature of the study design; no definite cause or effect can be stipulated and is possible only to show an association between various risk factors and the presence of musculoskeletal disorders, but not to demonstrate a relationship of cause and effect.

Once it has been verified that many students adopt incorrect postures and carry too much school backpack weight, it will be necessary to conduct further studies of an experimental nature whose intervention involves activities such as workshops on postural education, including a brief explanation of functional spine anatomy, transport and school backpack weight, correct ways of sitting, sleeping, watching $\mathrm{TV}$ and playing console games, in order to raise awareness throughout the school community about the problems of poor posture. In addition, one should also include the teaching and encouragement of regular exercise and specific stretching techniques and relaxation in school in order to minimize musculoskeletal disorders in school children.

\section{Conclusion}

This was a stratified and representative sample of students living in southern Portugal. We found that many students carried overweight school backpacks (above $10 \%$ of body weight of the subject). A high number of students had adopted incorrect postures when sitting, standing, carrying the backpack and picking up objects from the floor. Students who sat with the spine positioned wrongly at home and at school, as well as those who were standing incorrectly, were more likely to show symptoms of LBP. No association was identified between scoliosis and the adoption of incorrect postures, or carrying excess weight in backpacks.

\section{Conflict of interest}

None to declare.

\section{References}

[1] Hebert S, Xavier R, Pardini A Jr, Filho T. Ortopedia e Traumatologia: Princípios e prática. São Paulo: Artmed; 2003.

[2] Jayaratne K. Inculcating the ergonomic culture in developing countries: National healthy schoolbag initiative in Sri Lanka. Hum Factors 2012;54(6):908-24.

[3] Missaoui B, Portero P, Bendaya S, Hanktie O, Thoumie P. Posture and equilibrium in orthopedic and rheumatologic diseases. Neurophysiol Clin 2008;38(6):447-57.

[4] Chansirinukor W, Wilson D, Grimmer K, Dansie B. Effects of backpacks on students: Measurement of cervical and shoulder posture. Australian Journal of Physiotherapy 2001;47:110-16.

[5] Shamsoddini A, Hollisaz M, Hafezi R. Backpack Weight and Musculoskeletal Symptoms in Secondary School Students, Tehran, Iran. Iran J Public Health 2010;39(4): 120-25.

[6] Panagiotopoulou G, Christoulas K, Papanckolaou A, Mandroukas K. Classroom furniture dimensions and anthropometric measures in primary school. Appl Ergon 2004;35(2): 121-28.

[7] Rohlmann A, Mann A, Zander T, Bergmann G. Effect of an artificial disc on lumbar spine biomechanics: A probabilistic finite element study. Eur Spine J 2009;18(1):89-97.

[8] Hong Y, Fong D, Li J. The effect of school bag design and load on spinal posture during stair use by children. Ergonomics 2011;54 (12):1207-13. 
[9] Korovessis P, Koureas G, Zacharatos S, Papazisis Z. Backpacks, back pain, sagittal spinal curves and trunk alignment in adolescents: A logistic and multinomial logistic analysis. Spine (Phila Pa 1976) 2005;30(2):247-55.

[10] Chow D, Leung K, Holmes, A. Changes in spinal curvature and proprioception of schoolboys carrying different weights of backpack. Ergonomics 2007;50(12):2148-56.

[11] Chansirinukor W, Wilson D, Grimmer K, Dansie B. Effects of backpacks on students: Measurement of cervical and shoulder posture. Australian Journal of Physiotherapy 2001;47:110-16.

[12] Pascoe D, Pascoe D, Wang Y, Shim D, Kim C. Influence of carrying book bags on gait cycle and posture of youths. Ergonomics 1997;40(6):631-41.

[13] Chow D, Kwok M, Cheng J, Lao M, Holmes A, Au-Yang A, et al. The effect of backpack weight on the standing posture and balance of schoolgirls with adolescent idiopathic scoliosis and normal controls. Gait Posture 2006;24: 173-81.

[14] Jayaratnea K, Jacobsb K, Fernando D. Global healthy backpack initiatives. Work 2012;41:5553-57.

[15] Foerster M. Our Kids, Backpacks, and the Back Epidemic. Orthopaedic Practice 2003;15(3).

[16] Negrini S, Negrini A. Postural effects of symmetrical and asymmetrical loads on the spines of schoolchildren. Scoliosis $2007 ; 2: 8$.

[17] Lowe T, Edgar M, Margulies J,Miller N, Raso V, Reinker $\mathrm{K}$, et al. Etiology of Idiopathic Scoliosis: Current Trends in Research. J Bone Joint Surg Am 2000;82:1157-68.

[18] Negrini S, Carabalona R, Sibilla P. Backpack as a daily load for schoolchildren. The Lancet 1999;354:1974.

[19] Negrini S, Carabalona R. Backpacks on! Schoolchildren's perceptions of load, associations with back pain and factors determining the load. Spine (Phila Pa 1976) 2002;27(2):187-95.

[20] Negrini S, Politano E, Carabalona R, Tartarotti L, Marhetti M. The backpack load in schoolchildren: Clinical and social importance, and efficacy of a community-based educational intervention. A prospective controlled cohort study. Eura Medicophys 2004;40(3):185-90.

[21] Siambanes D, Martinez J, Butler E, Haider T. Influence of school backpacks on adolescent back pain. J Pediatr Orthop 2004;24:211-17.

[22] Cabinet of Statistics and Planning Education. [Internet]. Educação em números. Portugal. [accessed on 2013 May 15]. Available from: http://me2.addition.pt/data/http _-_www.gepe.min-edu.pt_np4__newsId=520\&fileName= GEPE_Setembro.pdf.

[23] Coelho L, Almeida V, Oliveira R. Lombalgia nos adolescentes: Identificação de factores de risco psicossociais. Estudo epidemiológico na Região da Grande Lisboa. Revista Portuguesa de Saúde Pública 2005;23(1):81-90.

[24] Vital E, Melo M, Nascimento A, Roque A. Raquialgias na entrada da adolescência: Estudo dos factores condicionantes em alunos do 5.o ano. Revista Portuguesa de Saúde Pública 2006;24 (1):57-84.

[25] Kristjansdóttir G. Prevalence of self-reported back pain in school children: A study of sociodemographic differences. Eur J Pediatr 1996;155:984-86.

[26] Schaeffer R, Mendenhall W, Ott L. Elementary Survey Sampling. Fourth Edition. California: Duxbury Press, Belmont, 1990.

[27] Amendt L, Ause-Ellias K, Eybers J, Wadsworth C, Nielsen D, Weinstein S. Validity and reliability testing of the Scoliometer. Phys Ther 1990;70(2):108-17.
[28] Murrell G, Coonrad R, Moorman C, Fitch R. An assessment of the reliability of the Scoliometer. Spine (Phila Pa 1976) 1993;18(6):709-12.

[29] Karachalios T, Sofianos J, Roidis N, et al. Ten-Year followup evaluation of a school screening program for scoliosis. Spine 1999;24(22):2318-24.

[30] Grivas T, Vasiliadis E, Koufopoulos G, Segos D, Triantafyllopoulos G, Mouzakis V. Study of trunk asymmetry in normal children and adolescents. Scoliosis 2006;1(19): $1-8$.

[31] Scoliosis Australia. [Internet]. About Scoliosis: Symptoms, causes, treatment. [accessed on 2013 May 20]. Available from: http://www.scoliosis-australia.org/scoliosis/ about_scoliosis.html.

[32] Grivas T, Vasiliadis E, Mihas C, Triantafyllopoulos G, Kaspiris A. Trunk asymmetry in juveniles. Scoliosis 2008; 3:13.

[33] Bunnell W. An objective criterion for scoliosis screening. J Bone Joint Surg Am 1984;66:1381-87.

[34] Grivas T, Wade M, Negrini S, O'Brien J, Maruyama T, Hawes M, et al. SOSORT consensus paper: School screening for scoliosis. Where are we today? Scoliosis 2007;2:17.

[35] Bunnell W. Selective Screening for Scoliosis. Clinical Orthopaedics and Related Research 2005;434:40-45.

[36] Bunnell W. Outcome of spinal screening. Spine (Phila Pa 1976) $1993 ; 18: 1572-80$

[37] Morrissy R. School Screening for Scoliosis. Spine 1999;24 (24):2584-91

[38] Viviani G, Budgell L, Dok C, Tugwell P. Assessment of accuracy of the scoliosis school screening examination. Am J Public Health 1984;74:497-98.

[39] Adobor R, Rimeslatten S, Steen H, Brox J. School screening and point prevalence of adolescent idiopathic scoliosis in 4000 Norwegian children aged 12 years. Scoliosis 2011;6:23.

[40] Oliveira R. A lombalgia nas crianças e adolescentes. Estudo epidemiológico na região da Grande Lisboa [Master Thesis]. Lisbon: Universidade Técnica de Lisboa 1999.

[41] NHS Centre for Reviews and Dissemination. Effective Health Care: Acute and chronic low back pain. Royal Society of Medicine Press, 2000: ISSN 0965-0288.

[42] Rebolho M. Efeitos da educação postural nas mudanças de hábitos em escolares das $1^{\mathrm{a}} \mathrm{a} 4^{\mathrm{a}}$ séries do ensino fundamental. [Master Thesis]. São Paulo: Faculdade de Medicina da Universidade de São Paulo 2005.

[43] Hong Y, Li J, Wong A, Robinson P. Effects of load carriage on heart rate, blood pressure and energy expenditure in children. Ergonomics 2000;43(6):717-27.

[44] Skaggs D, Early S, D’Ambra P, Tolo V, Kay R. Back pain and backpacks in school children. Journal of Pediatric Orthopaedics 2006;26(3):358-63.

[45] American Occupational Therapy Association [Internet]. [accessed on 2015 June 30]. Available from: www.aota.org.

[46] World Health Organization. Physical Status: The Use and Interpretation of Anthropometry. Report of a WHO Expert Committee. WHO Technical Report Series no. 854. Geneva: WHO 1995.

[47] Dandurand F, Shultz T. Automatic detection and quantification of growth sports. Behavior Research Methods 2010;42(3):809-23.

[48] Matos M, Simões C, Carvalhosa S, Reis C. A saúde dos adolescentes portugueses: Estudo nacional da rede europeia HBSC /OMS (1998). FMH/PEPT 2000.

[49] Lopes J. O transporte de cargas em mochilas escolares e o desenvolvimento motor harmonioso das crianças. Estudo 
das repercussões biomecânicas agudas na marcha e na equilibração, com cargas diferenciadas. [Master Thesis]. Porto: Universidade do Porto 2002.

[50] Sheir-Neiss G, Kruse R, Rahman T, Jacobson L, Pelli J. The association of backpack use and back pain in adolescents.Spine (Phila Pa 1976) 2003;28(9):922-30.

[51] Grimmer K, Dansie B, Milanese S, Pirunsan U, Trott P. Adolescent standing postural response to backpack loads: A randomised controlled experimental study. BMC Musculoskeletal Disorders 2002;3:10.

[52] Asher M, Burton D. Adolescent idiopathic scoliosis: Natural history and long term treatment effects. Scoliosis 2006;1:2.

[53] Machida M. Cause of Idiopathic Scoliosis. Spine 1999; 24(24):2576-83.

[54] Scoliosis Research Society [Internet]. [accessed on 2013 Jan 20]. Available from: http://www.srs.org.

[55] Burwell R, Freeman B, Dangerfield P, et al. Etiologic theories of idiopathic scoliosis: Enantiomorph disorder concept of bilateral symmetry, physeally-created growth conflicts and possible prevention. Stud Health Technol Inform 2006;123:391-97.

[56] Anderson S. Spinal Curves and Scoliosis. Radiologic Technology 2007;79(1):44-65.

[57] Calvo-Muñoz I, Gómez-Conesa A, Sánchez-Meca J. Prevalence of low back pain in children and adolescents: A meta-analysis. BMC Pediatrics 2013;13:14.

[58] Onofrio A, Silva M, Domingues M, Rombaldi A. Acute low back pain in high school adolescents in Southern Brazil: Prevalence and associated factors. Eur Spine J 2012;21:1234-40

[59] Skoffer B, Foldspang A. Physical activity and low-back pain in schoolchildren. Eur Spine J 2008;17:373-79.

[60] Louw Q, Morris L, Grimmer-Somers K. The Prevalence of low back pain in Africa: A systematic review. BMC Musculoskeletal Disorders 2007;8:105.

[61] Vitta A, Martinez M, Piza N, Simeão S, Ferreira N. Prevalence of lower back pain and associated factors in students. Cad. Saúde Pública Rio de Janeiro 2011;27(8): 1520-28.

[62] Kovacs F, Gestoso M, Real M, López J, Mufraggi N, Méndez J. Risk factors for non-specific low back pain in schoolchildren and their parents: A population based study. Pain 2003;103:259-68.

[63] Gunzburg R, Balagué F, Nordin M, Szpalski M, Duyck D, Bull Det al. Low back pain in a population of school children. Eur Spine J 1999:8;439-43.

[64] Jones G, Macfarlane G. Predicting Persistent Low Back Pain in Schoolchildren: A Prospective Cohort Study. Arthritis \& Rheumatism (Arthritis Care \& Research) 2009;61(10): 1359-66.

[65] Tiira A, Paananen M, Taimela S, Zitting P, Järvelin M, Karppinen J. Determinants of adolescent health care use for low back pain. Eur J Pain 2012;16:1467-76.

[66] Korovessis P, Koureas G, Papazisis Z. Correlation between backpack weight and way of carrying, sagittal and frontal spinal curvatures, athletic activity, and dorsal and low back pain in schoolchildren and adolescents. J Spinal Disord Tech 2004;17(1):33-40.

[67] Trevelyan F, Legg S. Risk factors associated with back pain in New Zealand school children. Ergonomics 2011;54(3): 257-62.

[68] Shehab D, Al-Jarallah K. Nonspecific low-back pain in Kuwaiti children and adolescents: Associated factors. Journal of Adolescent Health 2005;36:32-35

[69] Watson K, Papageorgiou A, Jones G, Taylor S, Symmons D, Silman Aet al. Low back pain in schoolchildren: The role of mechanical and psychosocial factors. Arch Dis Child 2003;88:12-17.

[70] Jones G, Watson K, Silman A, Symmons D, Macfarlane G. Predictors of Low Back Pain in British Schoolchildren: A Population-Based Prospective Cohort Study. Pediatrics 2003;111:822-28.

[71] Grimmer K, Williams M. Gender-age environmental associates of adolescent low back pain. Applied Ergonomics 2000;31:343-60.

[72] Yao W, Luo C, Ai F, Chen Q. Risk Factors for Nonspecific Low-Back Pain in Chinese Adolescents: A Case-Control Study. Pain Medicine 2012;13:658-64.

[73] Vidal j, Borra's P, Ponseti F, Cantallops J, Ortega F, Palou P. Effects of a postural education program on school backpack habits related to low back pain in children. Eur Spine J 2012;22 (4):782-87.

[74] Hestbaek L, Leboeuf-Yde C, Kyvik K, Manniche C. The course of low back pain from adolescence to adulthood: Eight-year follow-up of 9600 twins. Spine (Phila Pa 1976) 2006;31(4):468-72.

[75] Hestbaek L, Leboeuf-Yde C, Kyvik K. Are lifestyle-factors in adolescence predictors for adult low back pain? A crosssectional and prospective study of young twins. BMC Musculoskeletal Disorders 2006; 7:27.

[76] Cardon G, Balague F. Letters. Spine 2005;30(9):1106-07.

[77] Brackley H, Stevenson J. Are children's backpack weight limits enough? A critical review of the relevant literature. Spine 2004;29(19):2184-90.

[78] Boćkowski L, Sobaniec W, Kułak W, Śmigielska-Kuzia J, Sendrowski K, Roszkowska M. Low back pain in schoolage children: Risk factors, clinical features and diagnostic management. Advances in Medical Sciences 2007;52(Suppl 1):221-23.

[79] Murphy S, Buckle P, Stubbs D. Classroom posture and selfreported back and neck pain in schoolchildren. Applied Ergonomics 2004;35:113-20.

[80] Sjolie A. Associations between activities and low back pain in adolescents. Scand J Med Sci Sports 2004;14:352-59.

[81] Watson K, Papageorgiou A, Jones G, Taylor S, Symmons D, Silman A et al. Low back pain in schoolchildren: Occurrence and characteristics. Pain 2002;97:87-92.

[82] Widhe T. Spine: Posture, mobility and pain. A longitudinal study from childhood to adolescence. Eur Spine J 2001;10:118-23. 